\title{
Field Comparison of Soil Moisture Sensing Using Neutron Thermalization, Frequency Domain, Tensiometer, and Granular Matrix Sensor Devices: Relevance to Precision Irrigation
}

\author{
Clinton C. Shock ${ }^{*}$, André B. Pereira ${ }^{2}$, Erik B. G. Feibert ${ }^{3}$, Cedric A. Shock ${ }^{4}$, \\ Ali Ibrahim Akin ${ }^{5}$, Levent Abdullah Unlenen ${ }^{6}$ \\ ${ }^{1}$ Malheur Experiment Station, Oregon State University, Ontario, USA \\ ${ }^{2}$ Department of Soil Science and Agricultural Engineering, State University of Ponta Grossa, Ponta Grossa, Brazil \\ ${ }^{3}$ Oregon State University, Malheur Experiment Station, Ontario, USA \\ ${ }^{4}$ Oregon State University, Malheur Experiment Station, Ontario, USA \\ ${ }^{5}$ Ankara Nuclear Agriculture and Animal Research Center, Ankara, Turkey \\ ${ }^{6}$ General Directorate of Agricultural Researches, Potato Research Institute, Ministry of Agriculture and Rural \\ Affairs, Nigde, Turkey \\ Email: *clinton.shock@oregonstate.edu
}

Received 2 December 2015; accepted 2 February 2016; published 5 February 2016

Copyright (C) 2016 by authors and Scientific Research Publishing Inc.

This work is licensed under the Creative Commons Attribution International License (CC BY).

http://creativecommons.org/licenses/by/4.0/

c) (i) Open Access

\begin{abstract}
The efficient use of irrigation water requires several kinds of information. One element of efficient irrigation scheduling is monitoring the soil moisture to assure that the crop irrigation goals are being met. Various soil moisture sensing devices were tested for irrigation scheduling in silt loam at the Malheur Agricultural Experiment Station, Oregon State University between 2001 and 2004. Neutron probes, frequency domain probes, tensiometers, granular matrix sensors, and Irrigas were compared as to their performance under field conditions at Ontario, Oregon, USA. Granular matrix sensors were tested as read automatically by a datalogger and read manually with a handheld meter. Practical suggestions are provided to use soil moisture sensors to the benefit of crop production and water conservation.
\end{abstract}

${ }^{*}$ Corresponding author.

How to cite this paper: Shock, C.C., et al. (2016) Field Comparison of Soil Moisture Sensing Using Neutron Thermalization, Frequency Domain, Tensiometer, and Granular Matrix Sensor Devices: Relevance to Precision Irrigation. Journal of Water Resource and Protection, 8, 154-167. http://dx.doi.org/10.4236/jwarp.2016.82013 


\section{Keywords}

\section{Soil Water, Irrigation Scheduling, Responsiveness, Soil Moisture Sensor, Porous Ceramic}

\section{Introduction}

Soil moisture monitoring is a well established method to govern irrigation scheduling [1]. Application of water at a criterion wetter than crop needs results in over-application of water and a potential loss of crop yield and quality [2] [3]. Irrigation that precisely matches crop soil water requirements can avoid unnecessary water losses and can optimize yield and quality [4]-[7].

Precise irrigation scheduling is necessary to optimize marketable yield of high value crops while conserving water and protecting surface water and groundwater quality. Irrigation scheduling is greatly facilitated by any soil moisture sensor which can provide timely and reliable information on soil water content or soil water potential. For a particular sensor to be useful for a particular crop and soil, it needs to respond rapidly and reliably to the range of variation of soil water status that is important for marketable yield and product quality. Sensor readings need to be meaningful to assist irrigation scheduling, avoiding excessively frequent or intensive irrigation. Several types of sensors were tested for their responsiveness and usefulness for irrigation scheduling in soils typical of the Treasure Valley of the Snake River Plain of Oregon and Idaho. Neutron probes [8], frequency domain sensors [9] [10], tensiometers [11], and granular matrix sensors [12] have been widely used for irrigation scheduling. Tensiometers and granular matrix sensors respond to soil water potential. The porcelain tip of the tensiometer takes up or releases water in the immediate vicinity of the tip in response to the dynamics of the soil water potential and the partial vacuum inside the tensiometer. The granular matrix sensor takes up or releases water to the soil in its immediate vicinity and responds with variable electrical resistance between its internal electrodes. The neutron probe and frequency domain sensors respond to volumetric soil water content but in very different ways. The neutron probe emits high speed neutrons into the soil and counts much lower speed neutrons that return following inelastic encounters with hydrogen atoms in the soil. The capacitance probes measure capacitance in various high frequencies in the immediate vicinity of the probe in the soil. In one experiment, sensors were tested that utilize air permeability of porous ceramics.

Air permeability of porous ceramics has been used to estimate soil water potential [13]. Air permeability of a specific porous ceramic is a function of its water content. As water dries from the ceramic, the pores allow the passage of air. The "initial bubbling pressure" (IBI) of a water saturated porous ceramic is the lowest applied pressure at which air permeability (bubbling) is observed. The IBI of a specific porous ceramic has been used to estimate whether a soil has reached a specific soil water potential, possibly an irrigation criterion. The National Center for Horticultural Research of EMBRAPA, Brasilia, Brazil developed "Irrigas" based on IBI of porous ceramics. Irrigas consists of a porous ceramic cup, a moveable container of water, a flexible tube, a transparent barrel, and a rigid thin plastic support. The porous ceramic cup is installed in the effective rooting zone of the crop and connected to a small transparent barrel by means of the flexible tube. The porous ceramic cup is designed to retard free air movement out of the cup until the soil and cup reach a predetermined water potential. To make a reading, the barrel is immersed in the container of water. The free air passage through the porous ceramic cup gets blocked whenever the soil water saturates the pores in the ceramic. When the soil dries, its moisture eventually drops below a critical tension value, and the porous cup becomes permeable to the passage of air. In dry soils when the barrel is immersed into the water, the meniscus (air-water boundary) rapidly moves upwards in the barrel to equalize it to the water level in the container. Whenever water enters the barrel, the soil is at least as dry as the calibration of the porous ceramic cup. The soil moisture is evaluated once a day to determine the moment to irrigate. In sandy soils the evaluation is made twice a day.

Various sensors were tested in four field trials over several years.

\section{Materials and Methods}

\subsection{Experiment 1}

Six soil moisture sensors were compared by their performance in response to wetting and drying in irrigated 
hybrid poplar (Populus deltoides x P. nigra) at the Malheur Experiment Station in Ontario, Oregon, 4358'55"N $117^{\circ} 01^{\prime} 27^{\prime \prime} \mathrm{W}, 683 \mathrm{~m}$ above mean seal level (amsl). The trees were planted in April 1997 on Nyssa-Malheur silt loam soil (coarse-silty, mixed, mesic Xerollic Durorthid) on a $4.27-\mathrm{m}$ by $4.27-\mathrm{m}$ spacing. The tree rows were oriented to the northwest. The trees were irrigated using a micro sprinkler system (R-5, Nelson Irrigation, Walla Walla, WA) with the risers placed between trees along the tree row at $4.27-\mathrm{m}$ spacing. The sprinklers delivered water at the rate of $3.6 \mathrm{~mm} /$ hour at $176 \mathrm{kPa}$ and a radius of $4.27 \mathrm{~m}$. The area used for the sensor performance trial was managed to receive $50.8 \mathrm{~mm}$ of water whenever the soil water potential at $0.20-\mathrm{m}$ depth reached -50 $\mathrm{kPa}$.

Two frequency domain Aquaflex sensors (Streat Instruments, Christchurch, New Zealand) were installed on September 14, 2000. Each 3-m long sensor was installed at 0.20-m depth along the tree row and between two trees. The two Aquaflex sensors were connected to an Aquaflex datalogger (Streat Instruments). On July 23, 2001, six types of soil moisture sensors were added to the study and were read daily at 9 AM for 40 days. One sensor of each type was installed in four replicates: two replicates each were installed adjacent to each of the existing Aquaflex sensors. The order of the sensors was randomized within each replicate to achieve a randomized complete block statistical design. The sensors in each replicate were installed at $0.20-\mathrm{m}$ depth in a line parallel to and $0.20 \mathrm{~m}$ from the Aquaflex sensors. The sensors in the four replicates were tensiometer (Irrometer SR, Irrometer Co. Inc, Riverside, CA, USA), granular matrix sensor (GMS, Watermark Soil Moisture Sensor model 200SS, Irrometer Co. Inc), neutron probe model 503 DR Hydroprobe (Boart Longyear, Martinez, CA), time domain reflectometry Moisture Point (E.S.I. Environmental Sensors Inc., Victoria, British Columbia, Canada), and two frequency domain devices, the Gro Point (E.S.I. Environmental Sensors Inc) and the Gopher (Cooroy, Queensland, Australia). The neutron probe and Moisture Point were capable of readings below the 20-cm depth, but only readings at $20 \mathrm{~cm}$ were used for comparisons. The four Gro Point sensors were connected to two Gro Point 3-channel dataloggers (E.S.I. Environmental Sensors Inc). The GMS were connected to an AM400 Soil Moisture Datalogger (M.K. Hansen Co., East Wenatchee, WA, USA). All other sensors were read manually at 9 AM from Monday through Friday.

The tensiometer and GMS required that a hole in the soil be made with a standard 22.2-mm (7/8-inch) diameter soil auger for installation. The tensiometers required regular resetting due to the column of water breaking suction around -60 to $-70 \mathrm{kPa}$. The Gro Point sensor was relatively compact and was easy to bury. Both the neutron probe and the Gopher required the installation of PVC access tubes for each monitored location. The Moisture Point used a $0.9 \mathrm{~m}$ long probe permanently installed at each location to be monitored. The Moisture Point probe required a hole driven with a rectangular rod provided by Environmental Sensors Inc for installation. The neutron probe, Gopher, and Moisture Point allowed measurement of soil moisture at different depths at each location. The Aquaflex required a horizontal 3-m trench dug to the depth of installation, $0.20 \mathrm{~m}$.

Both the neutron probe and Gopher required site specific calibration. One undisturbed core soil sample was taken in each instrument location during sensor installation. The soil samples were immediately placed in tin cans and weighed, then oven dried at $100^{\circ} \mathrm{C}$ for 48 hours and weighed again. Volumetric soil moisture content was calculated for the soil samples using the gravimetric method. After the sensors were installed, $50.8 \mathrm{~mm}$ of water was applied. On July 25, another set of soil samples was taken and volumetric soil moisture content was determined as before. The sensors were read at the same time as the soil samples were taken. The neutron probe was read as counts during 32 seconds. For calibration, the volumetric soil water content determined from the soil samples was regressed against the neutron probe and Gopher readings. The average soil moisture data from the neutron probe and from the tensiometers was compared using regression against the average soil moisture data for each of the other sensors. The GMS sensors were used to manage the irrigation. The entire area of the sensor comparison trial was irrigated when the GMS readings reached $-50 \mathrm{kPa}$.

\subsection{Experiment 2}

Six types of soil moisture sensors were compared by their performance in response to wetting and drying in drip-irrigated potato (Solanum tuberosum) at the Malheur Experiment Station at Ontario, Oregon, 43 $58^{\prime} 44^{\prime \prime} \mathrm{N}$ $117^{\circ} 01^{\prime} 03^{\prime \prime} \mathrm{W}, 676 \mathrm{~m}$ amsl. The sensors were Aquaflex, Gro Point, Moisture Point, neutron probe, tensiometer, and GMS as described above. The GMS were evaluated as read automatically by an AM400 datalogger and read manually with a hand-held meter, model 30 KTCD-NL (Irrometer Co. Inc.), as previously calibrated [15].

Potato seed of cultivar 'Mazama' was planted on April 26, 2002 in rows spaced $0.91 \mathrm{~m}$ apart. The potato seed 
pieces were spaced $0.23 \mathrm{~m}$ apart in the row. The soil was an Owyhee silt loam (coarse-silty, mixed, mesic Xerollic Camborthid) with a pH of 8.1 and 2 percent organic matter. Drip tape (T-tape, T-systems International, San Diego, CA) was laid at 0.10 -m depth between two potato rows. The drip tape had emitters spaced $0.305 \mathrm{~m}$ apart and nominal emitter flow rate of $0.5 \mathrm{~L} / \mathrm{hr}$. The potato crop was irrigated daily to replace the previous day's evapotranspiration. Potato evapotranspiration $\left(\mathrm{ET}_{\mathrm{c}}\right)$ was calculated with a modified Penman equation [14] using data collected at the Malheur Experiment Station by an AgriMet weather station (United States Bureau of Reclaimation, Boise, Idaho). In mid-June the sensor study was installed along one of the potato rows. Six types of sensors were installed between the drip tape and the potato row. The sensors were installed $0.20 \mathrm{~m}$ from the drip tape and $0.25 \mathrm{~m}$ from the potato row. The sensors were centered at $0.23-\mathrm{m}$ depth. The experimental design was a randomized complete block design with four replicates. These instruments were installed, managed, and calibrated as in experiment 1 above.

From July 15 to July 25 and again from July 30 to August 7, the potato row containing the sensors was not irrigated so that sensor performance could be evaluated under variable soil moisture, during both wetting and drying conditions. Sensor readings were evaluated for 30 days near 9 AM.

\subsection{Experiment 3}

Four types of soil moisture sensors were evaluated in furrow-irrigated onion (Allium cepa) grown on Owyhee silt loam (coarse-silty, mixed, mesic, Xerollic Camborthid) over various wetting and drying cycles at the Mal-

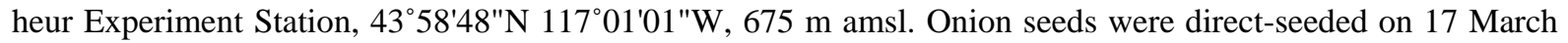
2004 in double-rows on 0.56-in beds. The double onion rows were spaced $76 \mathrm{~mm}$ apart. The types of soil moisture sensors were tensiometers with pressure transducers (Irrometer Model RA, Irrometer Company, Inc.), ECH2O 10 dielectric aquameter (Decagon Devices, Pullman, Washington), GMS, and Irrigas (National Center for Horticultural Research of EMBRAPA, Brasilia, Brazil. On 15 July 2004 the sensitive parts of the sensors were installed at $0.20-\mathrm{m}$ depth below double rows of onions. The statistical design was a randomized complete-block with 4 replicates and the replicates were placed $20 \mathrm{~m}$ apart down a 1.25-ha furrow-irrigated field.

Tensiometers, GMS, and ECH2O 10 dielectric aquameters were attached to three AM416 multiplexers (Campbell Scientific, Logan UT, USA) that in turn were wired to a CR10X datalogger (Campbell Scientific). The CR10X datalogger was programmed to take hourly readings. Two temperature sensors were installed at $0.20 \mathrm{~m}$ depth and the datalogger was programed to make temperature corrections of GMS readings [15]. Data were collected from the datalogger using a laptop computer from 15 July to 30 September 2004. Each replicate contained 2 tensiometers, 2 GMS, 1 ECH2O 10 dielectric aquameter, and 2 Irrigas. The Irrigas operated on the principle of air permeability of porous ceramics explained above. The Irrigas had a nominal calibration of -25 $\mathrm{kPa}$ and when we subjected Irrigas to progressive amounts of suction, the porous ceramic freely bubbled air at $-25 \mathrm{kPa}$ in the laboratory out of the soil. Irrigas readings were taken every day at $9 \mathrm{AM}$.

The ECH2O 10 dielectric aquameters were calibrated against volumetric soil water content by taking two soil samples near each probe centered at $0.20 \mathrm{~m}$ depth, once when the soil was relatively wet, and once when the soil was relatively dry, and also by preparing oven dry soil and placing the probes in the oven dry soil at the end of the trial. Gravimetric data were converted to volumetric water contents using the soil bulk density.

Prior to starting the sensor performance trial, the onions were irrigated at $-25 \mathrm{kPa}$ based on average GMS readings [3]. With the establishment of this experiment in the onion field, the onions in the entire sensor calibration trial were irrigated when the average GMS reading reached $-25 \mathrm{kPa}$ on July 17 and 22 . Since the Irrigas had not provided positive readings at $-25 \mathrm{kPa}$, the next five irrigations were delayed until at least half of the 8 Irrigas sensors indicated the need for irrigation.

\subsection{Experiment 4}

Automated reading of GMS was done in a furrow-irrigated Greenleaf silt loam (fine-silty, mixed, mesic Xerollic

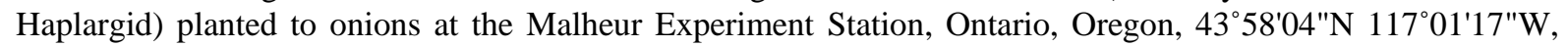
$675 \mathrm{~m}$ amsl. Onion seeds were planted 14 March 2003 in double-rows on 0.56-in beds. The double onion rows were spaced $76 \mathrm{~mm}$ apart. The response of two independent sets of GMS to irrigation events and the termination of irrigation was read automatically using an AM400 datalogger and a Watermark Monitor (Irrometer Co. Inc.). Data from the last 41 days of the growing season were used for comparison purposes due to the larger range of soil water potential that occurred as the irrigation season ended and the soil dried. 
The sensors were installed with their centers $0.20 \mathrm{~m}$ deep directly below the onion plants. The sensors were installed in the lower part of the 0.6 ha field where the furrow irrigations were less effective at wetting the soil. Six GMS and a temperature probe were connected to an AM400 datalogger which read the sensors three times a day. Data were recovered from the AM400 using a palm computer as previously described [16]. Seven GMS and a temperature probe were connected to a Watermark Monitor. A laptop computer and the WaterGraph program (Irrometer Co., Inc.) were used to set the sensor data collection frequency at 15 minutes. Data were recovered from the Irrometer Watermark Monitor using a laptop and the WaterGraph program.

\subsection{Interpretation of Data}

The soil moisture data from each type of sensor was graphed over time to determine if the data provided meaningful wetting and drying trends. In experiments 1,2 , and 3 , soil moisture monitoring devices were compared using regression analyses over the range of wetting and drying observed in the particular trial (NCSS 97, Statistical System for Windows, [17]).

\section{Results}

\subsection{Experiment 1}

The coefficient of determination $\left(r^{2}\right)$ for the regression equation for the neutron probe at $0.20-\mathrm{m}$ depth was 0.93 at $P=0.01$. The regression equation was used to transform the neutron probe readings to volumetric water content. A calibration for the Gopher sensor was not possible due to a lack of correlation between the Gopher readings and the volumetric soil water content determined from the soil samples. The tensiometer, Watermark, neutron probe, Gro Point, and Aquaflex responded to the wetting and drying cycles of the soil (Figure 1). The
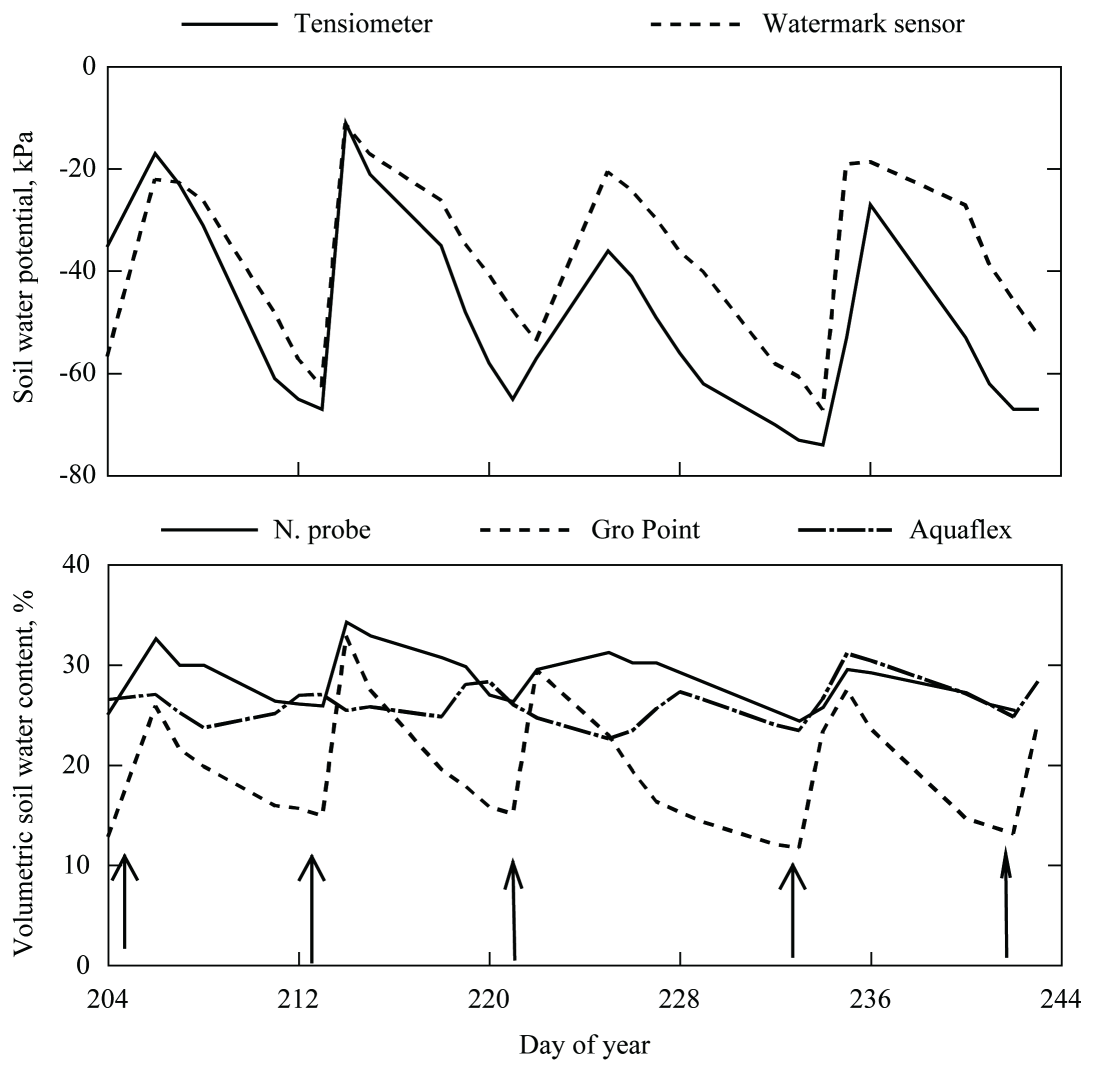

Figure 1. Soil moisture data over time for five types of soil moisture sensors in Experiment 1. Arrows denote irrigations with $50.8 \mathrm{~mm}$ of water applied. The Moisture Point sensor was not available during this time due to repairs being made. Malheur Experiment Station, Oregon State University, Ontario, OR, 2001. 
Aquaflex sensors were less responsive to the soil drying between irrigations than the neutron probe and the Gro Point sensor was more responsive than the neutron probe. The lower responsiveness of the neutron probe than the Gro Point was not surprising since the response volume of the neutron probe is larger and integrates less rapidly changing soil moisture deeper in the profile. The magnitude of the drying indicated by the Gro Point was beyond what occurred. All sensors showed correlations $\left(r^{2}>0.7\right)$ to the neutron probe $(P=0.001)$ and correlations $\left(r^{2}>0.5\right)$ to the tensiometer $(P=0.001$ to $P=0.01$ ) except the Moisture Point sensor (Figure 2 and Figure 3 ). Furthermore the Moisture Point estimates of soil water were substantially lower than the neutron probe data (Figure 2 and Figure 3).
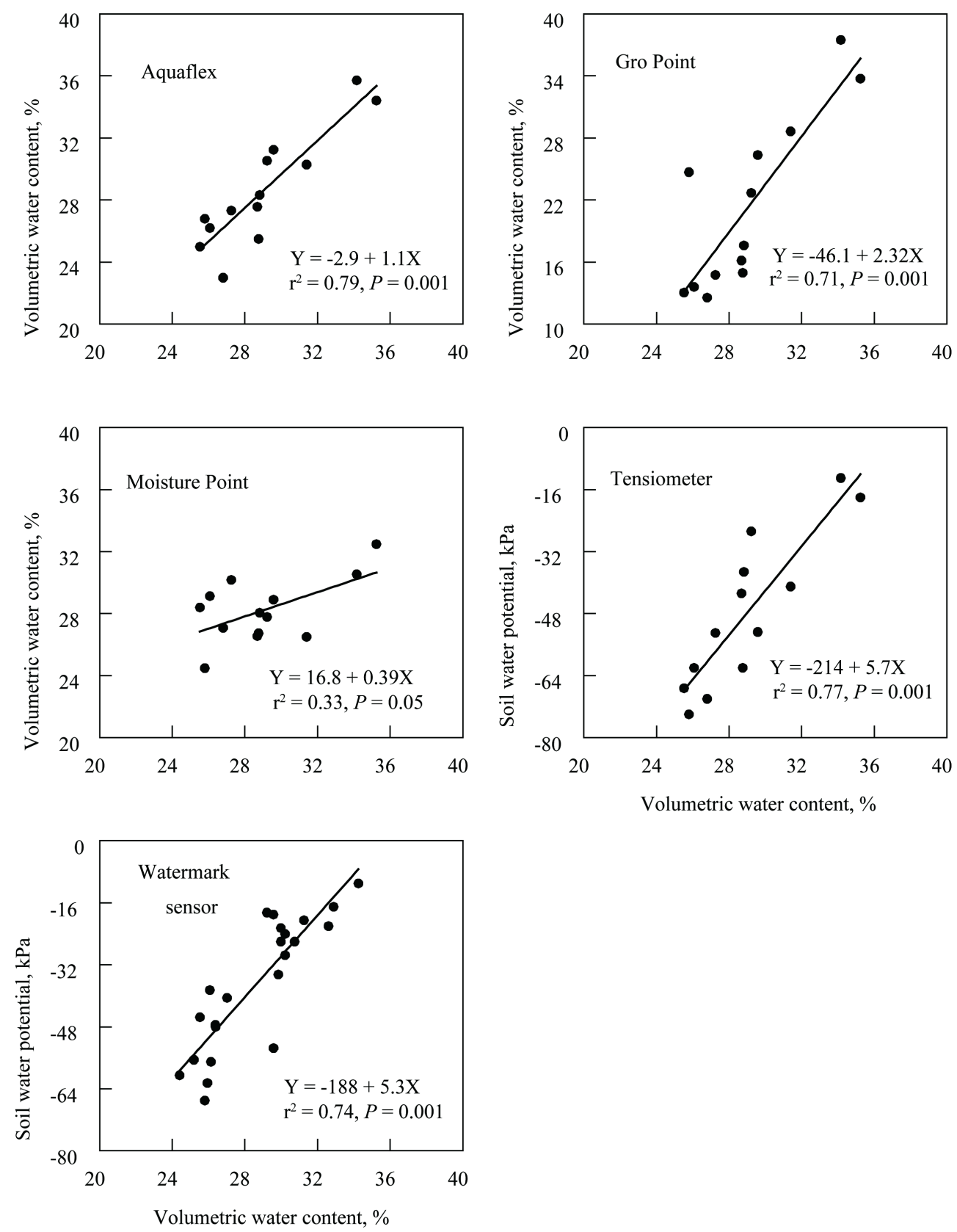

Figure 2. Volumetric soil water content measured in Experiment 1 by a neutron probe (X axis) regressed against soil moisture data (Y axis) measured by 5 types of soil moisture sensors. Data points for the Aquaflex sensor are the average of two sensors. Data points for the other sensors are the average of four sensors. Malheur Experiment Station, Oregon State University, Ontario, OR, 2001. 

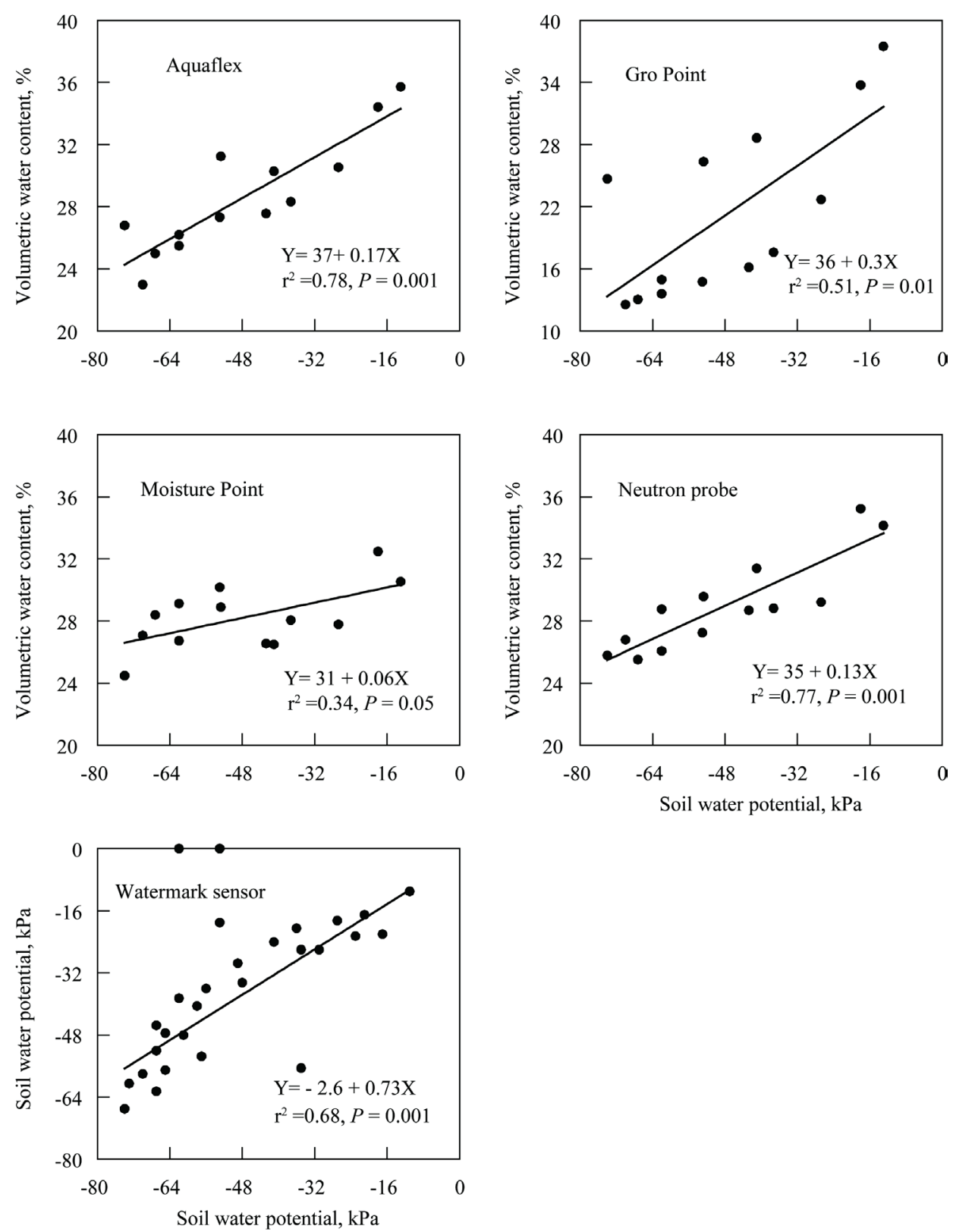

Figure 3. Soil water potential measured in Experiment 1 by tensiometers (X axis) regressed against soil moisture data (Y axis) measured by 5 types of soil moisture sensors. Data points for the Aquaflex sensor are the average of two sensors. Data points for the other sensors are the average of four sensors. Malheur Experiment Station, Oregon State University, Ontario, OR, 2001.

\subsection{Experiment 2}

The tensiometer, GMS, and neutron probe responded closely to the wetting and drying cycles of the soil (Figure 4). The Gro Point responded, but the amplitude of the response showed less fluctuation than that of the neutron probe. The Gro Point's variations could have been greater than the neutron probe, since the neutron probe measures soil water in a larger soil volume, including deeper soil that presumably would dry less. The Moisture Point was the least responsive to the wetting and drying cycles of the soil compared to the other sensors. For undetermined reasons, the Aquaflex datalogger only collected 3 days of data; this did not allow for conclusive results.

Readings of GMS by both the AM400 datalogger and the 30 KTCD-NL meter showed close correlations to tensiometer readings (Figure 5). The AM400 and the 30 KTCD-NL readings of different GMS were fairly 

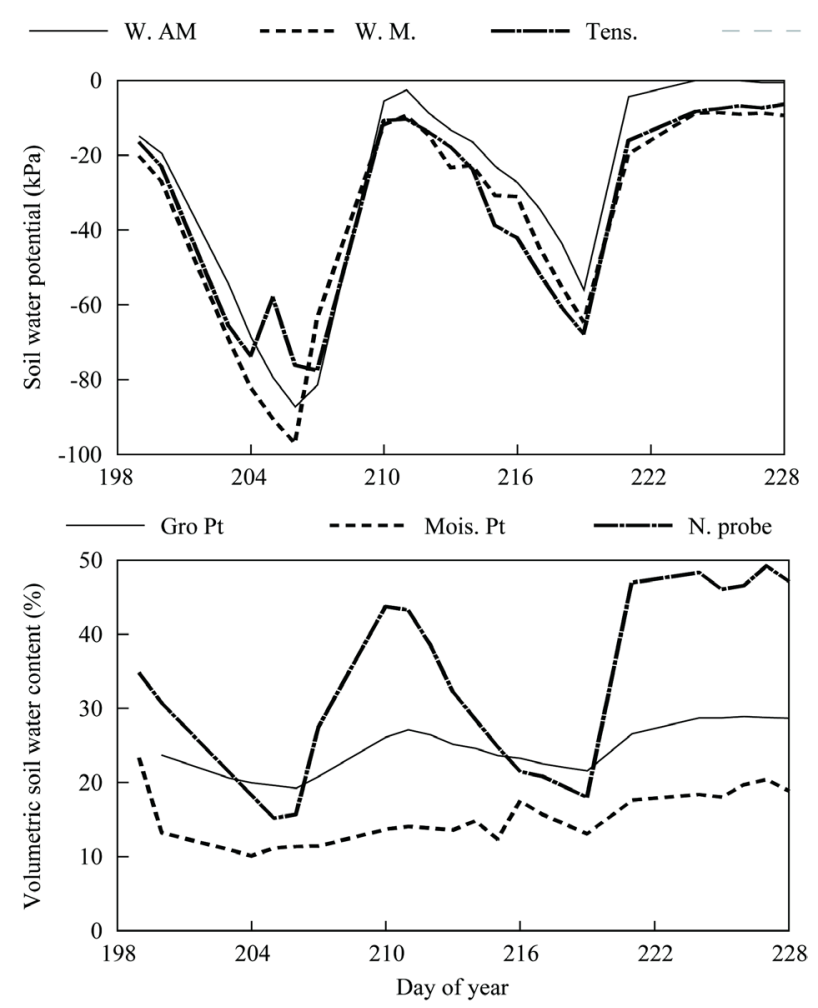

Figure 4. Soil moisture over time for five types of soil moisture sensors in Experiment 2, tensiometers (Tens.), Watermark soil moisture sensors read by a AM400 datalogger or manually (W. AM or W. M.), Gro Point (Gro Pt), Moisture Point (Mois. Pt) and neutron probe (N. probe). Malheur Experiment Station, Oregon State University, Ontario, OR, 2002.
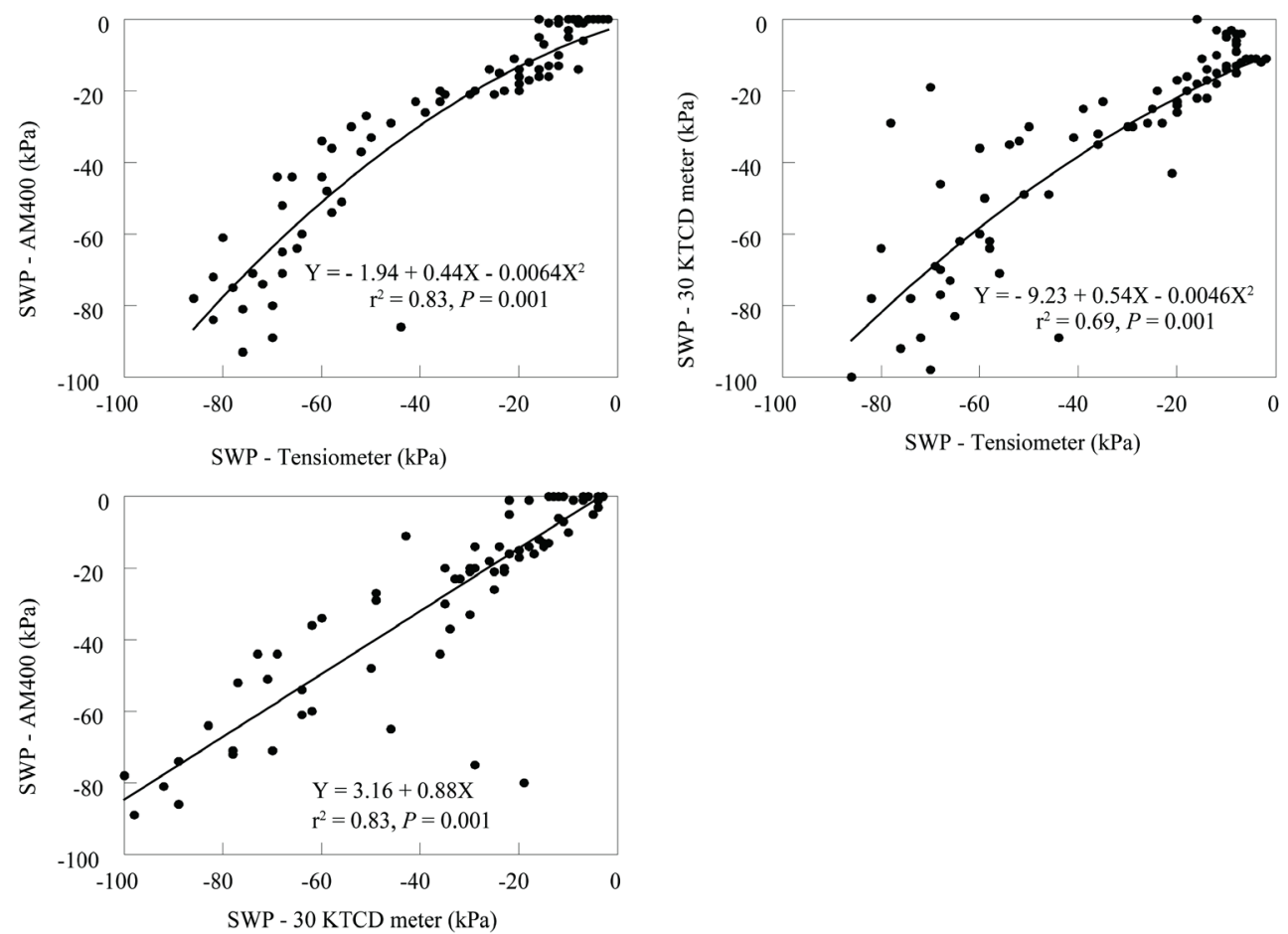

Figure 5. Regressions of soil water potential (SWP) measured in Experiment 2 by three instruments. Malheur Experiment Station, Oregon State University, Ontario, OR, 2002. 
closely correlated to each other; both instruments used similar equations to convert Watermark sensor electrical resistance to soil water potential (Shock et al. 2001).

All sensors showed correlations $\left(r^{2}>0.6\right)$ to the neutron probe $(P=0.001)$ except the Moisture Point sensor and Aquaflex (Figure 6). The Gro Point estimates of soil water were often lower than the neutron probe (Figure 4 and Figure 6). The Moisture Point estimates of soil water were substantially lower than the neutron probe and Gro Point (Figure 4 and Figure 6).
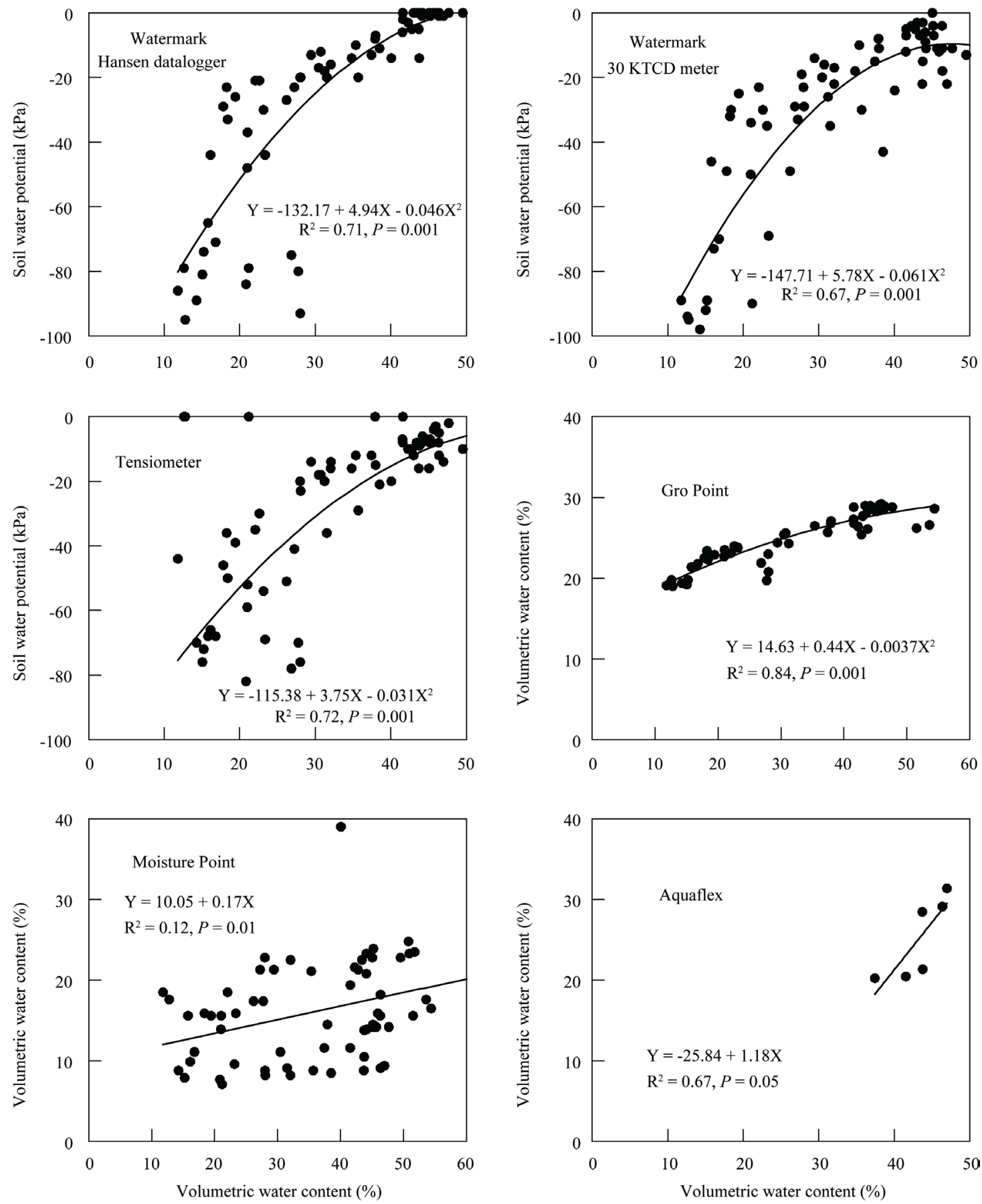

Figure 6. Volumetric soil water content measured in Experiment 2 by a neutron probe (X axis) regressed against soil moisture data (Y axis) measured by 6 types of soil moisture sensor. Malheur Experiment Station, Oregon State University, Ontario, OR, 2002. 


\subsection{Experiment 3}

All the sensors used in this study had low unit cost and simple installation. There were two episodes of irrigation based on GMS readings at $-25 \mathrm{kPa}$ and five irrigation events based on the Irrigas criterion (Figure 7). Both tensiometers and GMS had similar responses to wetting and drying of the soil (Figure 7).

It took about $4 \mathrm{~h}$ for all the tensiometers and all GMS to indicate that the soil at $0.20 \mathrm{~m}$ had reached saturation after the onset of each furrow irrigation episode. The relative similarity in responsiveness between tensiometers with pressure transducers and granular matrix sensors (GMS) was confirmed by regression with a coefficient of determination of $0.92(P=0.0001)$ (Figure 8$)$. The Irrigas had free air permeability close to $-35 \mathrm{kPa}$ for Owyhee silt loam in this trial (Figure 7).

Large changes in tensiometer readings from -10 to $-40 \mathrm{kPa}$ translated into small changes in water content readings for the ECH2O 10 dielectric aquameter (Figure 9). A comparison of the ECH2O 10 dielectric aquameter readings with soil volumetric water content from this field indicated that the readings were relatively flat and nonlinear in response to changes in volumetric soil water content (Figure 10). The relatively small changes in volumetric soil water content measured by the ECH2O 10 dielectric aquameter were unrealistic and the small changes in measurements occurred across the critical range of soil water potential for onion irrigation decisions, limiting the usefulness of the probe. The reasons for the low responsiveness of the ECH2O 10 dielectric aquameter to the soil water content were beyond the scope of this work.

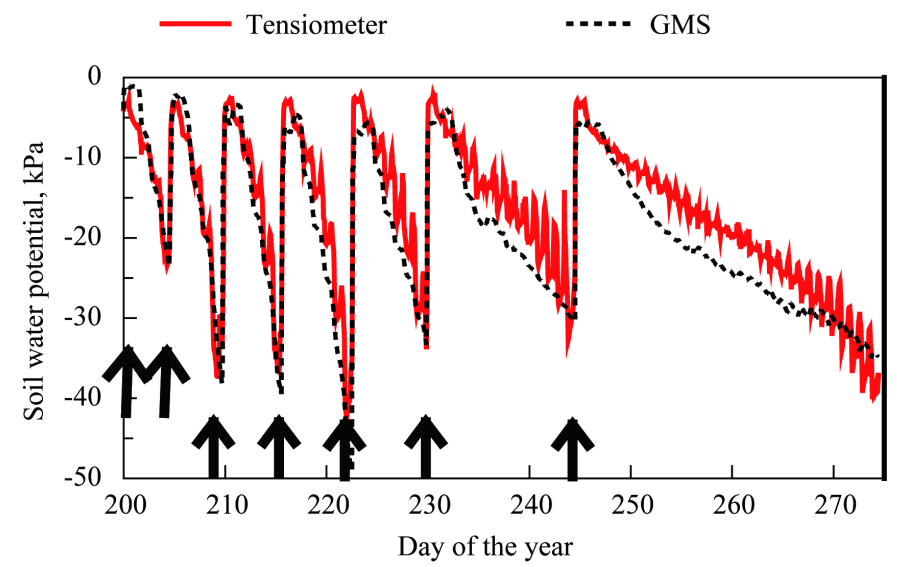

Figure 7. Soil water potential over time for tensiometers with transducers and granular matrix sensors in Experiment 3. Arrows denote furrow irrigations with $75 \mathrm{~mm}$ of water applied. Malheur Experiment Station, Oregon State University, Ontario, OR, 2004.

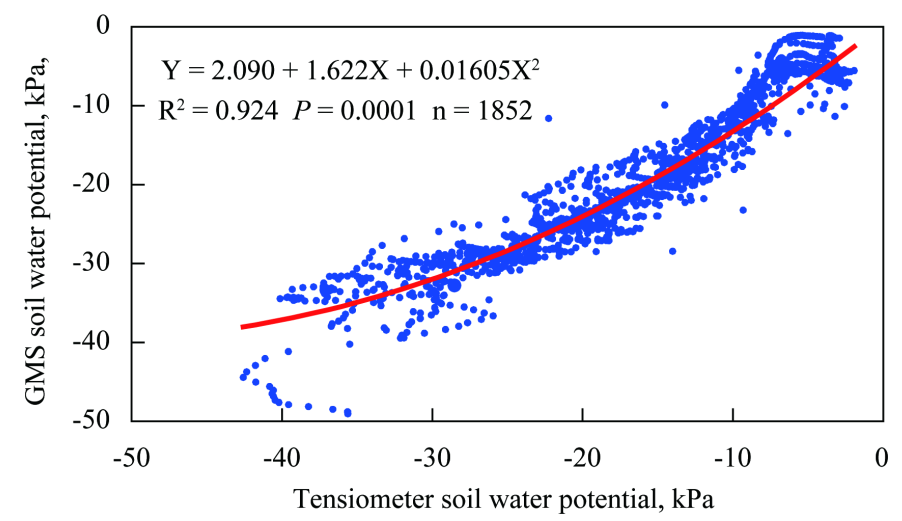

Figure 8. Soil water potential measured in Experiment 3 by a tensiometer with transducers ( $\mathrm{X}$ axis) regressed against soil moisture suction measured by a granular matrix sensor ( $\mathrm{Y}$ axis). Data points are the average of eight instruments. Malheur Experiment Station, Oregon State University, Ontario, OR, 2004. 


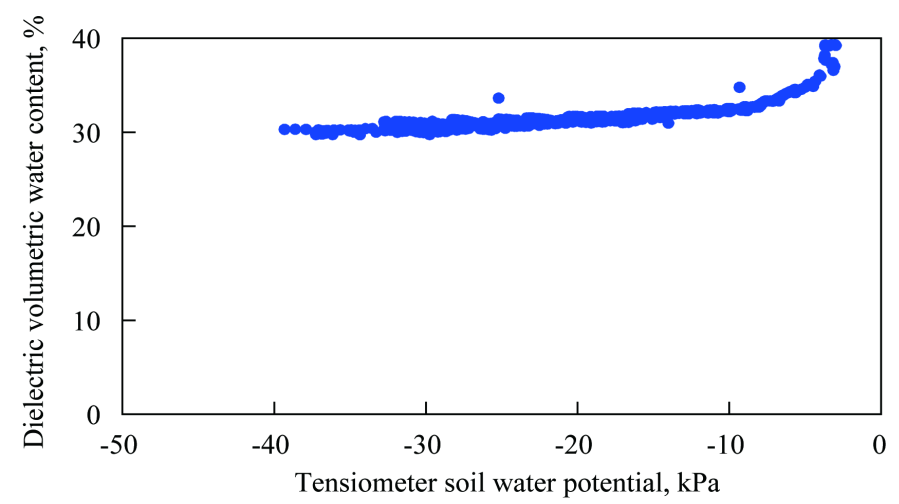

Figure 9. Soil water potential measured in Experiment 3 by a tensiometer with transducers (X axis) regressed against volumetric soil water content measured by an ECH2O 10 dielectric aquameter (Y axis). Data points for soil water potential are the average of eight tensiometers. Data points for the ECH2O 10 dielectric aquameter are the average of four sensors. Malheur Experiment Station, Oregon State University, Ontario, OR, 2004.

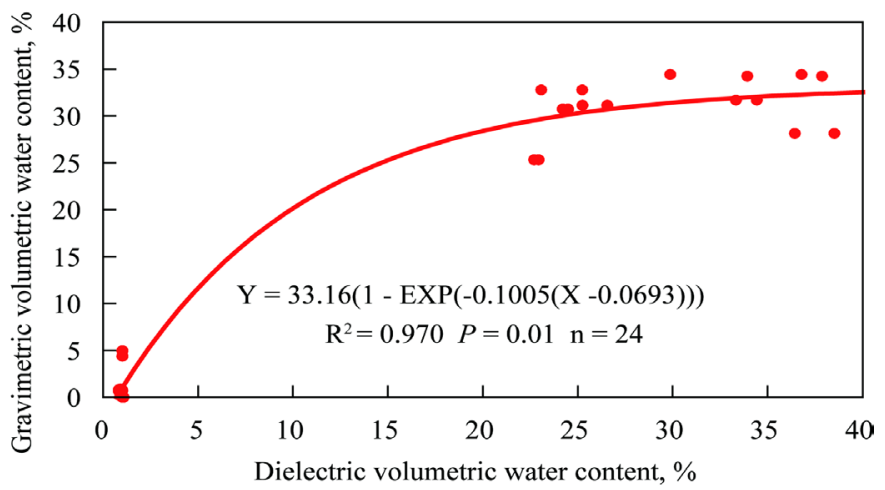

Figure 10. Regression of the volumetric soil water content measured by an ECH2O 10 dielectric aquameter ( $\mathrm{X}$ axis) against the classical gravimetric method ( $\mathrm{Y}$ axis). Data points from each of four ECH2O 10 dielectric aquameters were compared with two soil samples in each of three soil moisture ranges. Malheur Experiment Station, Oregon State University, Ontario, OR, 2004.

\subsection{Experiment 4}

The automated collection of GMS data by an AM400 datalogger and a Watermark Monitor provided similar interpretation of wetting and drying cycles (Figure 11(a)). The GMS started responding to irrigation within one hour of the irrigation onset. Small differences in calibration equations were noted (Figure 11(b)) and slight differences in the interpretation of soil water potential near saturation were evident (Figure 11(a)).

\section{Discussion}

\subsection{Neutron Thermalization}

The neutron probe was used in two of the four experiments. The neutron probe readings clearly indicated changes in soil water content. Due to the site specific calibrations, the changes in soil water content readings accurately followed the soil water content, as has been described by others [8]. Where the soil texture is variable, such as the silt loam soils of Ontario, Oregon, the practical use of neutron probe soil water content data requires field by field calibration. Calibrated data can be accurately interpreted to meet crop irrigation requirements and avoid over irrigation. Neutron probe use was awkward, time consuming, and required safety precautions. Readings can be downloaded automatically from the probe to a computer, but neutron probe readings cannot be automated in the sense of continuous readings. 

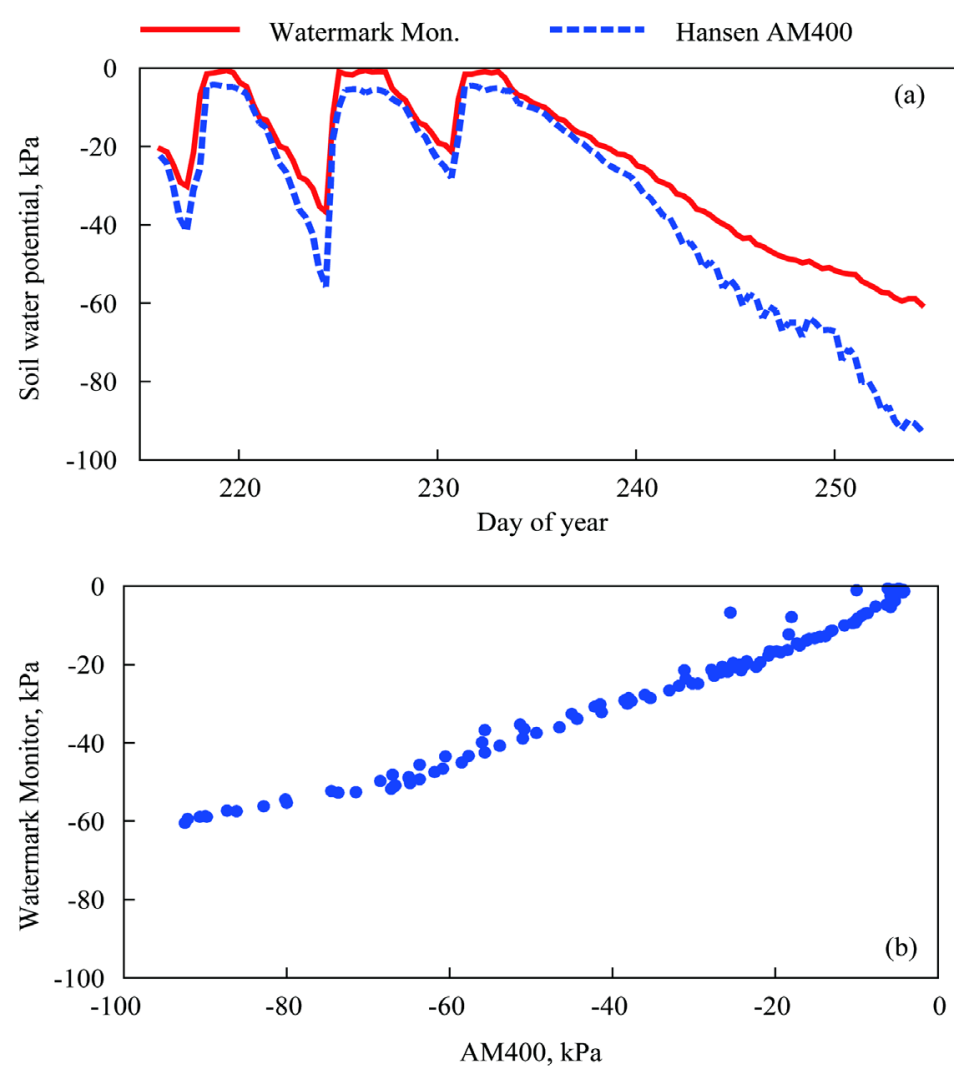

Figure 11. Response of Watermark soil moisture sensors to irrigation events and the termination of irrigation as measured by a Hansen AM400 datalogger and an Irrometer Watermark Monitor in Experiment 4. The average readings of an AM400 datalogger and a Watermark Monitor are compared over time (a) and over the measured range of soil water potential (b). Malheur Experiment Station, Ontario, OR, 2003.

\subsection{Frequency Domain Sensors}

The frequency domain sensors were more or less easy to automate. The ECH2O 10 dielectric aquameter was relatively easy to automate. The ECH2O 10 dielectric aquameter was used in only one experiment and the readings were relatively unresponsive to changes in soil water potential in the range of -10 to $-40 \mathrm{kPa}$ (Figure 9) and relatively unresponsive to changes to volumetric soil water content in the range of $23 \%$ to $38 \%$ (Figure 10). Limited ECH2O 10 dielectric aquameter responsiveness suggests the need for site specific calibrations prior to use. The ECH2O 10 is a $10 \mathrm{~cm}$ long, single panel capacitance soil moisture probe that uses low-frequency signals. Decagon Devices discontinued the ECH2O 10, replacing it with a high-frequency two pronged capacitance soil moisture probe (10HS), with much less susceptibility to the effects of soil salinity and soil texture.

Gro Point could be conveniently automated with proprietary dataloggers. The Gro Point readings followed wetting and drying cycles in the two experiments where they were used (Figure 1 and Figure 4) with inconsistent results. The changes in soil water were overestimated in Experiment 1 (Figure 2) and underestimated in Experiment 2 (Figure 6). These results suggest that the Gro Point would benefit from site specific calibrations prior to use. The need for site specific calibrations noted here for both the Gro Point and ECH2O 10 dielectric aquameter is consistent with the work of Evett who tested a variety of capacitance probes in widely divergent soils and recommended site specific calibrations [9]. Gopher readings were not closely associated with changes in soil water. With the Aquaflex, the interpretation of soil wetting and drying trends were ambiguous in Experiment 1 .

\subsection{Tensiometers}

Variations in soil water were clearly shown by tensiometers in the three experiments where they were used and 
the interpretations of the results were clear. The tensiometers with pressure transducers used in experiment 3 were easily automated. Due to variation in the tensiometer reading by time of day (Figure 7), visual readings at a consistent time of day as done here undoubtedly helped assure data quality in experiments 1 and 2 . The tensiometers required servicing twice during the 76 days of the trial 3. More frequent servicing to replace lost water should be expected when soils are not maintained as wet as in these experiments.

\subsection{Granular Matrix Sensors}

Granular matrix sensors were used in all four experiments and were very responsive to wetting and drying in the soils used in these experiments (Figure 1, Figure 4, Figure 7 and Figure 11). The GMS have limitations in reading soil water potential in soils wetter than $-10 \mathrm{kPa}$ (Figure 5 and Figure 8), as has been described previously [15], and in responding in coarse textured soils [12].

The three methods for automated reading of GMS in several trials were all convenient. The AM400 was helpful for following and scheduling irrigation events in the field due to its graphic display. The Watermark Monitor provided convenient settings for datalogger reading frequency, easy retrieval, and automatic interpretation of the data. The Campbell Scientific dataloggers plus peripheral equipment had great flexibility for reading GMS, as has been shown by complex designs of GMS and their use in controlling irrigations [18].

\subsection{Air Permeability of Porous Ceramics}

The model of "Irrigas" tested here in only one comparison experiment, appeared to provide a clear signal for irrigation scheduling at $-35 \mathrm{kPa}$ in silt loam, and failed to signal the nominal specification of $-25 \mathrm{kPa}$. Since previous research had shown furrow irrigations at a criterion of $-27 \mathrm{kPa}$ optimized long-day onion yield and grade on silt loam soil [3], a nominal signal at $25 \mathrm{kPa}$ could have provided a useful irrigation scheduling tool. The Irrigas equipment configuration used had limited usefulness, since water stress sensitive vegetable crops have many different irrigation criteria, and the ideal criteria are complex since they also vary by climate, soil type, and irrigation system [7].

Soil particles in contact with a porous ceramic can interfere with air permeability [13]. From results of this trial, it is possible that the silt loam interfered with the air permeability. One might predict greater interference by fine textured soils and less interference with coarse textured soils. One might predict greater interference at relatively high (wetter) soil water potential and less interference at relatively low (drier) soil water potential. In the present experiment the soil texture was fine and the soil water potentials were wet.

\section{Conclusion}

The soil moisture measurement devices tested here generally provided data closely correlated with each other. Neither the neutron probe nor the Irrigas were convenient to automate. The frequency domain sensors were more or less easy to automate but were not adequately reliable without engineering improvements or soil specific calibrations. Both tensiometers and granular matrix sensors were relatively easy to calibrate and the readings were readily useful for irrigation scheduling.

\section{Acknowledgements}

Technical assistance of student employees Scott Jaderholm, Kendra Nelson, Autumn Tchida and Christie Linford is greatly appreciated. Funding for two sensor comparison trials was made available by the Agricultural Research Foundation at Oregon State University, Corvallis, Oregon, USA. Additional support was provided by Oregon State University and Hatch funds. Many thanks are also owed to the Conselho Nacional de Desenvolvimento Cientifico e Tecnologico for the provision of the Post-Doctoral scholarship, Brazil, as well as to the Fundação Araucária of Brazil for the concession of a productivity fellowship in research.

\section{References}

[1] Charlesworth P. and Stirzaker, R.J. (2003) Irrigation Scheduling by Soil Water Status. In: Stewart, B.A. and Howell, T.A., Eds., Encyclopedia of Water Science, Marcel Dekker, Inc., New York, 528-531.

[2] Eldredge, E.P., Holmes, Z.A., Mosley, A.R., Shock, C.C. and Stieber, T.D. (1996) Effects of Transitory Water Stress on Potato Tuber Stem-End Reducing Sugar and Fry Color. American Potato Journal, 73, 517-530. 
http://dx.doi.org/10.1007/BF02851697

[3] Shock, C.C., Feibert, E.B.G. and Saunders, L.D. (1998) Onion Yield and Quality Affected by Soil Water Potential as Irrigation Threshold. HortScience, 33, 1188-1191.

[4] Shock, C.C., Feibert, E.B.G. and Saunders, L.D. (2000) Irrigation Criteria for Drip-Irrigated Onions. HortScience, 35, 63-66.

[5] Shock, C.C., Feibert, E.B.G., Seddigh, M. and Saunders, L.D. (2002) Water Requirements and Growth of Irrigated Hybrid Poplar in a Semi-Arid Environment in Eastern Oregon. Western Journal of Applied Forestry, 17, 46-53.

[6] Shock, C.C. and Feibert, E.B.G. (2002) Deficit Irrigation of Potato. In: Moutonnet, P., Ed., Deficit Irrigation Practices, Food and Agriculture Organization of the United Nations, Rome, Water Reports 22, 47-55.

http://www.fao.org/docrep/004/Y3655E/Y3655E00.htm

[7] Shock, C.C. and Wang F.-X. (2011) Soil Water Tension, a Powerful Measurement for Productivity and Stewardship. HortScience, 46, 178-185.

[8] Evett, S.R. (2003) Measuring Soil Water by Neutron Thermalization. In: Stewart, B.A. and Howell, T.A., Eds., Encyclopedia of Water Science, Marcel Dekker, Inc., New York, 889-893.

[9] Evett, S.R., Laurent, J.P. Cepuder, P. and Hignett, C. (2002) Neutron Scattering, Capacitance, and TDR Soil Water Content Measurements Compared on Four Continents. 17th World Congress of Soil Science, 14-21 August 2002, Bangkok, 1021-1. (CD-ROM)

[10] Evett, S.R. and Steiner, J.L. (1995) Precision of Neutron Scattering and Capacitance Moisture Gauges Based on Field Calibration. Soil Science Society of America Journal, 59, 961-968. http://dx.doi.org/10.2136/sssaj1995.03615995005900040001x

[11] Hubbell, J.M. and Sisson, J. (2003) Soil Water Potential Measurement by Tensiometers. In: Stewart, B.A. and Howell, T.A., Eds., The Encyclopedia of Water Science, Marcel Dekker, New York, 904-907.

[12] Shock, C.C. (2003) Soil Water Potential Measurement by Granular Matrix Sensors. In: Stewart, B.A. and Howell, T.A., Eds., The Encyclopedia of Water Science, Marcel Dekker, New York, 899-903.

[13] Kemper, W.D. and Amemiya, M. (1958) Utilization of Air Permeability of Porous Ceramics a Measure of Hydraulic Stress in Soils. Soil Science, 85, 117-124. http://dx.doi.org/10.1097/00010694-195803000-00001

[14] Wright, J.L. (1982) New Evapotranspiration Crop Coefficients. Journal of Irrigation and Drainage Division, ASCE, 108, $57-74$.

[15] Shock, C.C., Barnum, J.M. and Seddigh, M. (1998) Calibration of Watermark Soil Moisture Sensors for Irrigation Management. In: Proceedings of the International Irrigation Show, Irrigation Association, San Diego, 139-146.

[16] Shock, C.C., Corn, A., Jaderholm, S., Jensen, L.B., and Shock, C.A. (2001) Evaluation of the AM400 Soil Moisture Datalogger to Aid Irrigation Scheduling. In Proceedings of the International Irrigation Show, Irrigation Association, San Diego, 111-116.

[17] Hintze, J.L. (2000) NCSS 97 Statistical System for Windows, Number Cruncher Statistical Systems, Kaysville, Utah.

[18] Shock, C.C. Feibert, E.B.G., Saunders, L.D. and Eldredge, E.P. (2002) Automation of Subsurface Drip Irrigation for Crop Research. World Congress on Computers in Agriculture and Natural Resources, American Society of Agricultural Engineers, Iguacu Falls, 809-816. 